\title{
Informed Consent in High-Risk Renal Transplant Recipients
}

\author{
G. Cocchiara, A.I. Lo Monte, G. Romano, M. Romano, and G. Buscemi
}

\begin{abstract}
Before performing a clinical, diagnostic, and/or therapeutic action, the doctor is required to provide the patient with a bulk of information defined as informed consent. This expression was used for the first time in 1957 during a court case in California and the two words-informed and consent-are used together to underline the fact that the patient cannot give his or her true consent without first receiving correct information concerning the medical act in question. With regard to the medicolegal aspects governing organ transplants, despite the bulk of detailed work performed by health service workers involved in this surgical field with the aim of preparing adequate informed consent models, this has not yet been accompanied by the necessary legislative development. The informed consent model to be presented to the kidney transplant candidate should include a detailed description of the recipient's comorbidity and should aim at reducing the number of medicolegal actions, which have become more and more frequent in the last few years due to the ever increasing number of patients considered as suitable for transplantation. Informed consent, therefore, should not be a mere bureaucratic formality to be obtained casually, but should be carefully stipulated together with the patient by the transplant surgeon. It is, in fact, an indispensable condition for transforming a potentially illegal action, that is, the violation of an individual's psychophysical integrity, into a legal one.
\end{abstract}

$\mathbf{B}^{\mathrm{E}}$ EFORE PERFORMING A CLINICAL, diagnostic, and/or therapeutic action, the doctor is required to provide the patient with a bulk of information defined as informed consent. This expression was used for the first time in 1957 during a court case in California, and the two words - informed and consent - are used together to underline the fact that the patient cannot give his or her true consent without first receiving correct information concerning the medical act in question.

Because nowadays more and more patients take legal action against the medical profession, the patient's well-being has to be weighed against the most adequate diagnostic and/or therapeutic approach. Although this concept is not clearly expressed in the Italian civil code, it derives from Article 13 of the Italian Constitution, which states that "personal liberty is inviolable," and Article 23, which states that "the protection of their liberty is a fundamental right of all citizens." ", Article 33 of the Health Reform Law No. 833/78 excludes the possibility of performing diagnostic investigation and treatment without the patient's consent. ${ }^{3}$ The doctor is obliged to inform the patient of the risks and benefits of the treatment proposed, of any other possible alternative therapeutic approaches, and also of any possible complications involved.
Although it is clear that informed consent does not exclude the doctor from any possible responsibility regarding the diagnostic and/or therapeutic action, if the patient has not received sufficient information before this action, the omission is considered as legally relevant. A doctor who has not previously obtained the patient's informed consent is legally responsible, even when the actual treatment has been performed more or less correctly. ${ }^{4}$

In the Italian legal code, there are no rules establishing inequivocally just how such consent should be proposed to the patient and, in fact, the printed forms provided are unable to offer complete, specific information.

\section{DISCUSSION}

The medicolegal aspects governing organ transplants, despite the bulk of detailed work performed by health service workers involved in this surgical field with the aim of preparing adequate informed consent models, has not yet

From the Department of General Surgery, University of Palermo, Palermo, Italy.

Address reprint requests to Gerlando Cocchiara, PhD, University of Palermo, 5 Vespro Street Palermo 90100, Italy.

(c) 2009 by Elsevier Inc. All rights reserved. 360 Park Avenue South, New York, NY 10010-1710 
been accompanied by the necessary legislative development. In a recent study conducted by Edward et al, which assessed the completeness and adequacy of the informed consent proposals presented to patients who were about to undergo kidney transplantations, there proved to be a great deal of variation in the aspects regarding risks and complications, which were at times mentioned and at others, not. ${ }^{5}$

Several authors have reported that the last 20 years have seen an improvement in kidney transplant results, with increased survival rates and improved quality of life of transplanted patients compared with those with end-stage renal diseases (ESRD) undergoing dialysis. ${ }^{6-8}$ Whereas the increase in the incidence of ESRD has led to an exponential increase in transplant requests, there has not been a corresponding increase in the number of organs made available. In the last few years, an attempt has been made to resolve this problem by using kidney donors defined as "marginal" or "suboptimal," because of age or other risk factors, such as high blood pressure, diabetes, or severe vascular diseases linked to the organ. ${ }^{9}$ At the same time, there has also been an increase in kidney transplant requests in patients with ESRD who also present other diseases, such as cardivascular diseases, diabetes mellitus, obesity, or neoplastic risk. ESRD subjects often suffer from peripheral arteriopathy, which may well prove to be an important cause of the technical failure of a kidney transplant, and can even increase the risk of amputation of the lower limbs. ${ }^{10}$ Diabetic patients undergoing kidney transplants have a higher risk of mortality and of reduction in the long-term graft duration than nondiabetic patients. ${ }^{11}$ Obesity is not an absolute kidney transplant contraindication, although it should be borne in mind that a transplanted obese patient has a greater risk of suppuration of the incision, together with a higher rate of delayed graft function, and will also show an increased incidence of diabetes after the transplantation. ${ }^{12-17}$

With regard to transplants in cancer patients, an active neoplasia is obviously an absolute contraindication to kidney transplantation, as it leads to an increased risk of metastases. A previous history of cancer, however, does not completely exclude the possibility of a transplant; the risk of neoplastic relapse, in fact, depends on the type of tumor involved and the period of time elapsing between the neoplasia and the transplant. ${ }^{18}$

In a recent study, Kandaswamy et al report that patients with extrarenal comorbidity produce different results according to whether a living or dead donor is involved; the former leads to a much higher survival rate. ${ }^{19}$ Assuming that kidney transplantation is not a lifesaving therapeutic approach, when the patient is affected not only by ESRD but also by certain conditions of comorbidity as mentioned earlier, he or she should be adequately informed before surgery about the increased risk involved in the procedure in terms of morbidity and mortality rate.

The informed consent model to be presented to the kidney transplant candidate should include a detailed description of the recipient's comorbidity and should aim at reducing the number of medicolegal actions, which have become more and more frequent in the last few years due to the ever increasing number of patients considered as suitable for transplantation. It is therefore necessary each time to draw up a specific informed consent form that is as personalized as possible for kidney transplant candidates with conditions of high-risk comorbidity. The wording should include a reference to problems that may aggravate the situation if the patient should be offered a suboptimal organ. ${ }^{9}$ The basic aim is, on the one hand, to defend the work of the surgical team, and on the other, to guarantee the rights of the patients involved. An informed consent model suitable for such high-risk patients should therefore be detailed, precise, and personally adapted to the recipient concerned, bearing in mind of course that the kidney transplant improves the duration and quality of life of individuals with ESRD. The patient should also be accurately informed about the surgical procedure implicated in the kidney transplantation. A personalized model should be used in order to include the particular conditions of comorbidity of the transplant patient, such as obesity, diabetes, vascular diseases and/or anomalies, possible neoplastic risks, and excretory tract anomalies, which lead to a higher complication risk and which may lower the possibility of surgical success.

Informed consent, therefore, should not be a mere bureaucratic formality to be obtained casually, but should be carefully stipulated together with the patient by the transplant surgeon. It is, in fact, an indispensable condition for transforming a potentially illegal action, that is, the violation of an individual's psychophysical integrity, into a legal one.

\section{CONCLUSION}

In conclusion, kidney transplantation is not a lifesaving surgical technique, and the prospective recipient should therefore evaluate the proposal with extreme care. All the information regarding the risks and the benefits should be highlighted in the informed consent, which should represent an act of faith linking the transplant team and the recipient; the patient should also take into consideration the experience of the surgical team and of the transplant center involved.

\section{REFERENCES}

1. Articolo 13 Costituzione della Repubblica Italiana

2. Articolo 23 Costituzione della Repubblica Italiana

3. Articolo 33 Legge 23 Dicembre 1978 No. 833. Istituzione del servizio sanitario nazionale. Gazzetta Ufficiale della Repubblica Italiana no. 360, 28 Dicembre 1978

4. Corte di Cassazione Civile, Sez. III, Sentenza 8/7/1994 No. 6464

5. Edward AG, Weale AR, Morgan JD: Informed consent in renal transplant. Postgrad Med J 81:188, 2007

6. Evans RV, Manninen DL, Garrison LP Jr, et al: The quality of life of patients with end-stage renal disease. N Engl J Med 28:553, 1985

7. Wolfe RA, Ashby VB, Milford EL, et al: Comparision of mortality in all patients on dialysis, patients on dialysis awating 
transplantation, and recipients of a first cadaveric traslant. N Engl J Med 341:1725, 1999

8. Schnuelle P, Lorenz D, Trede M, et al: Impact of renal cadaveric transplantation on survival in end-stage renal failure: evidence for reduced mortality risk compared with hemodialysis during long-term follow-up. J Am Soc Nephrol 9:2135, 1998

9. Persson MO, Persson NH, Källén R, et al: Kidneys from marginal donors: views patients informed consent. Nephrol Dial Transplant 17:1497, 2002

10. Jassal SV, Krahn MD, Naglie G, et al: Kidney transplantation in the elderly: a decision analysis. J Am Soc Nephrol 14:187, 2003

11. Holley JL, Monagh J, Byer B, et al: An examination of the renal transplant evalutation process focusing on cost and the reason for patient exclusion. Am J Kidney Dis 32:567, 1998

12. Pirsch JD, Armbrust MJ, Knechtle SJ, et al: Obesity a risk factor following renal transplantation. Transplantation 59:631, 1995

13. Meier-kriesche HU, Arndorfer JA, Kaplan B: The impact of body mass index on renal transplant outcomes: a significant independent risk factor graft failure and patient death. Transplantation 73:70, 2002

14. Humar A, Ramcharan T, Denny AM, et al: Are wound complications after a kidney transplant more common with modern immunosoppression? Transplantation 72:1920, 2001

15. Johnson DW, Isbel NM, Broun AM, et al: The effect of obesity on renal transplant outcome. Transplantation 74:675, 2002

16. Kasiske BL, Snyder JJ, Gilbertson D, et al: Diabetes mellitus after transplantation in the United States. Am J Transplant 3:178, 2003

17. Singh D, Lawen J, Alkuhudair W: Does pretransplant obesity affect the outcome in kidney transplant recipients? Transplant Proc 37:717, 2005

18. Kälble T, Lucan M, Nicita G, et al: Eau guideline on renal transplantation. Eur Urol 47:156, 2005

19. Kandaswamy R, Kasiske B, Ibrahim H, et al: Living or deceased donor kidney transplants for candidates with significant exstrarenal moebidity. Clin Transplant 20:346, 2006 